\title{
Do real ao Fictício: como atua o Design de Personagens na criação de uma personagem biográfica para um livro ilustrado
}

From Real to Fictional: how

Character Design works in creating a biographical character for a Picture Book

Carolina Tanabe Cervantes ${ }^{[1]}$, Mônica Lima de Faria ${ }^{[2]}$

\begin{abstract}
Resumo: Este trabalho tem como objetivo explorar uma metodologia de design de personagens, bem como expor as questões que englobam o projeto de criação dos mesmos, tendo como resultado a concepção final de uma personagem biográfica dedicada à criação de um livro ilustrado. Os objetivos desta pesquisa consistem em elencar os dados teóricos juntamente com a prática, e através disso apresentar os resultados obtidos. No que contempla a metodologia, esta pesquisa é qualitativa, de caráter exploratório, com revisões bibliográficas e documentais, e busca gerar maior familiaridade com os temas apresentados.

Palavras-chave: Design de Personagens. Personagem Biográfico. Livro llustrado. Abstract: This project intend to explore a methodology of character design, as well as expose the subjects that concerns the creation of those matters, having as result the final concept of a biographical character for the design of a picture book. The main objectives of this research are to list both, theoretical data and practice, and to present
\end{abstract}

[1] Bacharel em Design Gráfico, UFPEL. carolinatanabe@hotmail.com

[2] Doutora em Comunicação Social, PUC-RS. monicalfaria@gmail.com 
the obtained results. Regarding the methodology, this is a qualitative research with an exploratory nature, bibliographical and documentary revisions, and it seeks to acquire conversance about the presented themes.

Keywords: Character Design. Biographical Character. Picture Book.

\section{INTRODUÇÃO}

Este artigo relaciona-se com os resultados obtidos em uma pesquisa maior, executada durante o Trabalho de Conclusão de Curso intitulado "O Livro llustrado da Vovó Kyoko: crônicas ilustradas sobre a minha avó". Neste trabalho foram estudados os temas livro ilustrado, design editorial e criação de personagens, a fim de criar uma obra ilustrada autoral e biográfica, que contém crônicas vividas em família ao lado da avó da autora, homônima, caracterizada como a personagem principal do livro, a "Vovó Kyoko". A ideia deste projeto surgiu a partir da página na rede social Facebook, intitulada "Vovó Kyoko", criada pela irmã da autora, na qual a mesma posta pequenos relatos sobre as pérolas proferidas pela avó, que são notavelmente cômicas, rendendo ótimos contos. Aqui, expõe-se um recorte dessa pesquisa, englobando os resultados obtidos a partir da aplicação de uma metodologia de Design de Personagens, que foi especificamente voltada para a criação de uma personagem biográfica.

É importante definir que, em sua forma mais básica, a personagem consiste na pura e simples imitação e representação do ser humano segundo Aristóteles (384 a 322 a.C.), visando a verossimilhança; enquanto o Design de Personagens em si tem por objetivo estruturar a personalidade, para que esta seja capaz de sustentar a construção narrativa. Assim, é correto afirmar que o Design de Personagens se volta à criação do personagem do ponto de vista psicológico, e seus aspectos visuais consistem em uma forma de transmitir esta personalidade ao leitor do livro ilustrado. Durante a fase de pesquisa e desenvolvimento desta etapa do trabalho, foi utilizada a metodologia de criação de personagens proposta no livro "Como Criar Personagens Inesquecíveis" (SEGER, 2006) como aporte teórico. 


\section{ESTRUTURAÇÃO DA PERSONAGEM}

O primeiro passo a se dar na construção de uma personagem corresponde à etapa de pesquisa (SEGER, 2006). Esta etapa possui uma grande importância, pois a personagem, bem como o contexto que a mesma está inserida, precisam fazer sentido, parecerem verídicos e palpáveis. Assegurar isto é justamente o papel da pesquisa, pois através dela, o autor pode angariar informações de um determinado contexto que deseja explorar. Dentro desta etapa temos a pesquisa geral e a pesquisa específica. A pesquisa geral consiste em simplesmente revisar o que já se conhece sobre um determinado assunto; são os conhecimentos mais básicos que são detidos naturalmente a partir das vivências individuais. Já a pesquisa específica corresponde a uma coleta de informações mais aprofundada, que é necessária para que se conheça coisas que não são tão óbvias ou difundidas sobre os assuntos que rodeiam o universo do personagem a ser criado. Para Seger (2006), os contextos que mais influenciam as personagens são suas culturas, o período histórico em que estão inseridas, onde vivem e as suas profissões. Deste modo, aqui faz-se necessário destrinchar um pouco da história da personagem Vovó Kyoko, sendo esta também a introdução de sua biografia, bem como a exploração de seus aspectos psicológicos mais complexos, uma vez que as histórias das personagens revelam os motivos de suas personalidades.

No caso de Vovó Kyoko, nota-se influência de uma cultura nipo-brasileira com fortes raízes nos hábitos japoneses, principalmente nos mais antigos, caracterizados pela rigidez ao ensinar crianças a terem disciplina: ela nasceu no ano de 1943 em uma colônia japonesa no estado do Paraná, onde morava com seu pai, mãe e seus 10 irmãos. Seu pai não sabia falar português, portanto, japonês é a língua materna de Vovó. Era expressamente proibido que ela e seus irmãos falassem português dentro de casa - todas as suas conversas precisavam passar pelo monitoramento do pai, por isso, ela aprendeu o português somente quando passou a conviver 
com colegas de escola que falavam o idioma. Sua criação foi muito rígida em comparação ao que se é visto atualmente - Vovó Kyoko aprendeu muito cedo a ajudar nas tarefas domésticas, a trabalhar no campo, a ter disciplina, respeitar hierarquias dentro e fora do lar, e a cuidar dos animais da casa. À primeira vista pode-se pensar que existem valores similares no Brasil, onde toda família bem estruturada ensine respeito e responsabilidades às suas crianças, ainda mais em tempos mais conservadores como antes, mas a grande questão da criação japonesa é que esta levava rigidez a um outro nível, onde não havia espaço para rebeldias, e malcriações eram severamente punidas. As crianças tinham responsabilidades, dentro e fora do lar, muito mais cedo do que era ou é comum para a realidade brasileira. Apesar de tais costumes apresentarem a rigidez com que seus pais a criaram, os mesmos sempre eram relatados por Vovó Kyoko (Fig. 1) com um forte tom de saudosismo e respeito por sua vida e criação.

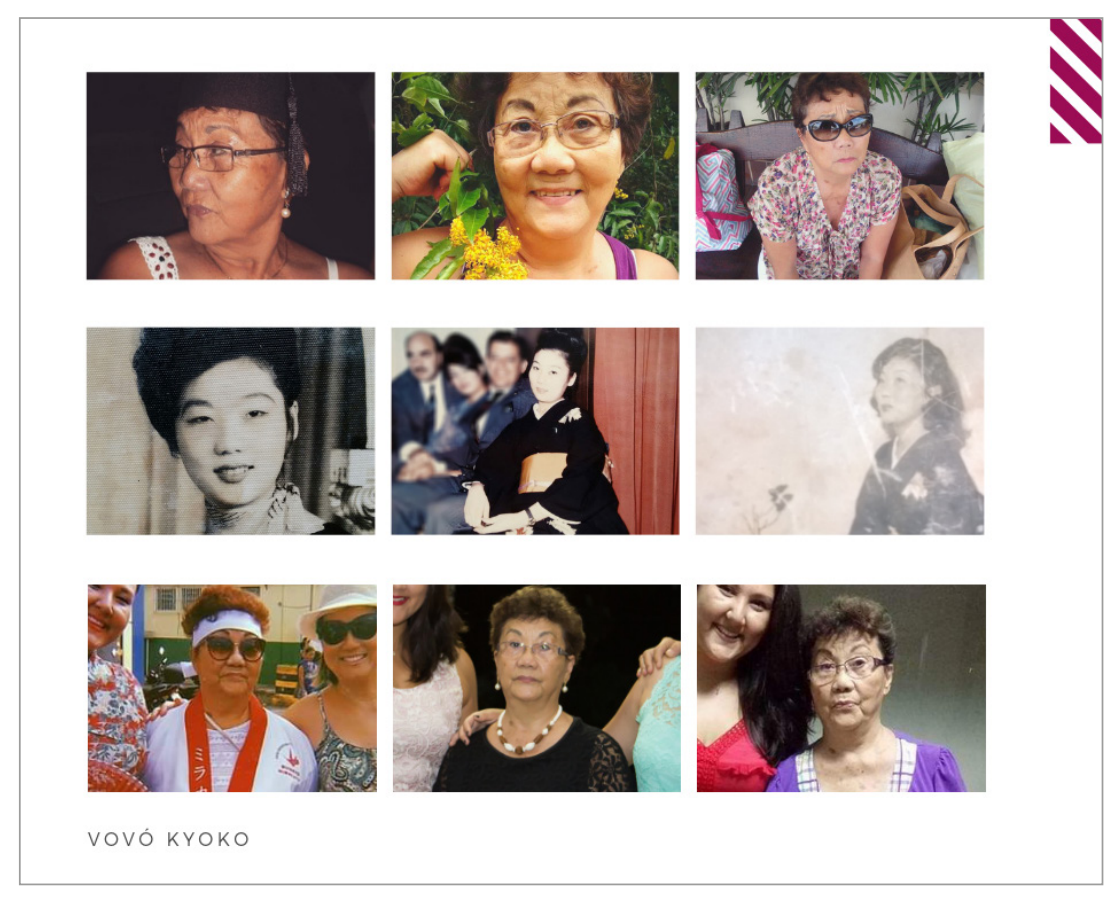

Figura 1. Fotos de Vovó Kyoko. Fonte: arquivo pessoal. 
A conclusão é que, ainda que nascida no Brasil, o caráter rígido, crítico, esforçado e de poucas palavras da personalidade de Vovó Kyoko, advém diretamente de sua infância, que seguiu os moldes japoneses que seus pais tiveram. Esses moldes influenciaram fortemente sua personalidade, sua forma de ver o mundo, de valorizar o trabalho duro, o seu contato com a cultura brasileira e como ela absorveu a mesma. Também é necessário frisar que, após adulta, Vovó Kyoko também morou no Japão, onde trabalhou em fábricas, e assim, obteve influência direta do país. Tal influência foi tão impactante e intrínseca que, ainda que, atualmente aposentada e com idade mais avançada, ela simplesmente não parou de trabalhar, passando tardes a fio executando atividades braçais, como capinar, limpar o terreno e cuidar de suas plantas.

No intuito de enriquecer as questões que envolvem a pesquisa específica, foi considerado de relevância apresentar uma análise de personagens (Fig. 2) já existentes no imaginário ficcional, que servem de inspiração para a construção da personagem Vovó Kyoko, além de que apresentá-los serve para que a personalidade de Vovó Kyoko seja melhor exemplificada.

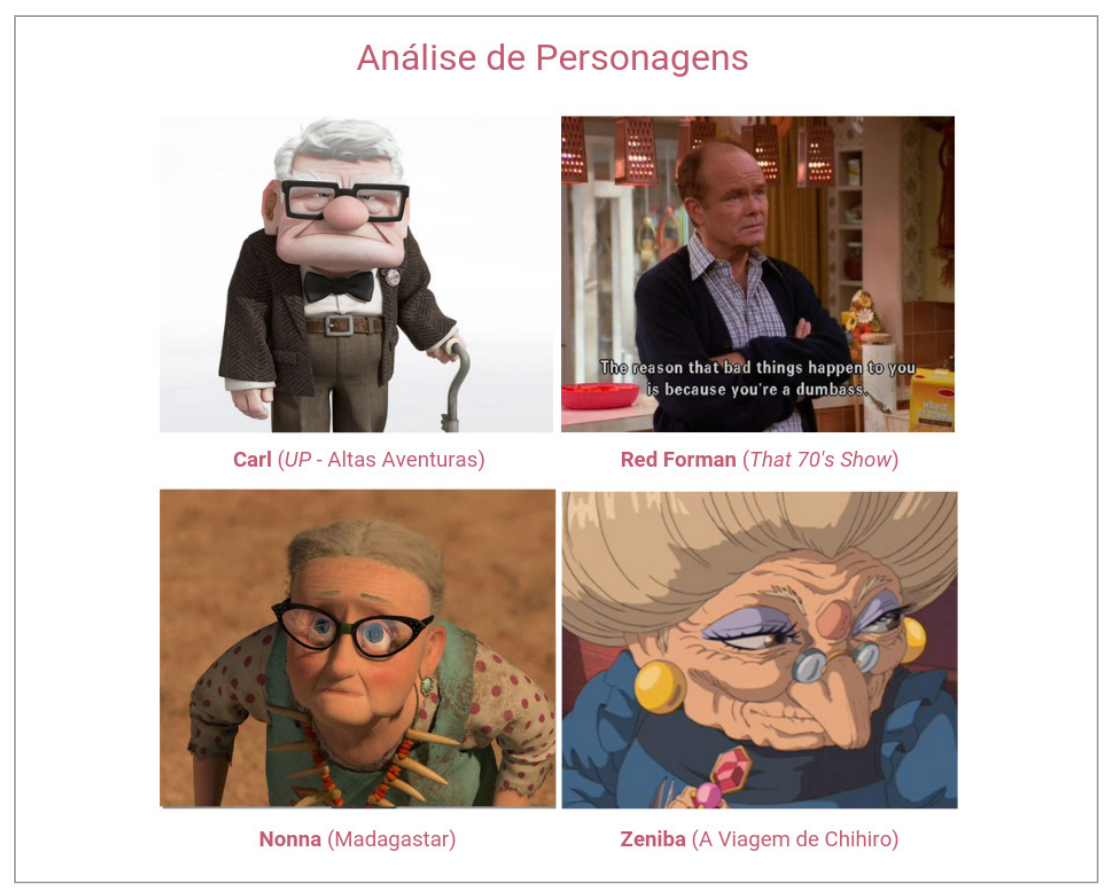

Figura 2. Personagens analisados. Fonte: coletânea realizada pela autora. 
O primeiro personagem elencado para ilustrar uma das facetas da Vovó é o senhor Carl Fredricksen, o "vovô" mal-humorado da animação UP - Altas Aventuras. Carl é uma das referências principais elencadas pois, assim como Vovó, ele também é um idoso que possui uma personalidade ranzinza, fugindo completamente do estereótipo da pessoa idosa mansa e completamente terna. Na animação, esse tom mal-humorado traz humor para a narrativa, assim como acontece nas crônicas de Vovó Kyoko, onde suas respostas curtas e grossas são os alívios cômicos das pequenas histórias.

O segundo personagem é Red Forman, personagem da série americana That 70's Show. Red é pai do protagonista, Eric Forman, e tem um mau humor digno de tornar suas falas excelentes alívios cômicos da trama. Além disso, Red também demonstra ser um senhor ranzinza e rígido, mas que defende seus filhos quando não é ele próprio quem grita com eles. A maneira como ele lida com duras verdades, principalmente quando se trata do filho, lembra bastante como Vovó profere suas falas indelicadas com verdades difíceis de ouvir.

A terceira personagem tem pouco destaque na trama em que aparece, mas marcou o público da animação ainda assim, trata-se da velhinha não tão simpática chamada genericamente de Nonna, do filme Madagascar. A senhora aparece no primeiro e no segundo filme, onde em diferentes situações, trava lutas corporais com o leão protagonista, Alex, atingindo-o diversas vezes com sua bolsa, e demonstra não ter medo do feroz animal. Nonna está ali para quebrar os padrões de "velhinha do tricô", enquanto proporciona mais uma vez alívio cômico através de seu temperamento forte. Personagens assim, apesar de parecerem exageradas demais, ou muito caricatas, são a exemplificação perfeita do temperamento de Vovó Kyoko.

A quarta personagem, Zeniba, é parte da animação japonesa $A$ Viagem de Chihiro, e é irmã gêmea da antagonista do longa, Yubaba. Em sua primeira aparição no filme, a senhora demonstra um temperamento difícil e tão rude quanto o de 
sua irmã gêmea, levando o expectador a confundi-la com a própria. No entanto, com o desenrolar da história, tomamos conhecimento de seus motivos e também de sua verdadeira personalidade: uma senhora que, por trás da "casca" rígida que exibe inicialmente, é terna, prestativa, com um forte senso de justiça, e que cuida daqueles que ama. Zeniba é uma maga poderosa, com autonomia, que se impõe, sendo mais uma personagem idosa para a soma das "vovós" empoderadas, assim como Vovó Kyoko.

Todos esses personagens apresentados possuem em comum a quebra do padrão do idoso extremamente terno, calmo ou indefeso. Compartilham entre si também a dualidade entre uma personalidade difícil, mas que no fundo é muito humana, sensata e protetora, exatamente como a Vovó é.

Observar figuras fictícias já existentes, e compará-las com as personagens desenvolvidas, é não só muito interessante, como também é agregador ao processo de criação. Tal atividade permitiu a visualização da personagem que estava em processo de criação com vida, e possibilitou que se imaginasse como seriam seus comportamentos, o que leva à segunda etapa de criação de personagens, onde foram definidas as consistências e paradoxos de Vovó Kyoko. Segundo Seger (2006), a criação da personagem inicia-se a partir do momento em que se tem uma primeira impressão da mesma, ou seja, no momento em que se idealiza uma primeira imagem. Neste caso, isso ocorreu durante a etapa de pesquisa, foi quando se criou uma noção de quem a personagem de fato é.

Vovó Kyoko é uma senhora idosa, de personalidade muito forte e marcante, nipo-brasileira, que ama gatos, é um tanto ranzinza e excessivamente sincera, beirando o desnecessário. Ela usualmente encontra-se num estado constante de mau humor e sem muita paciência para o que julga ser desnecessário, frívolo ou simplesmente estúpido, rebatendo sempre constatações e falas de outrem com a sinceridade que ela julga proporcional ao que foi dito, o que para alguns também se traduz em uma palavra: grosseria. Essas são suas 
consistências, são as características essenciais pelas quais ela é sempre lembrada. No entanto, embora Vovó seja alguém muito difícil de se lidar, é curioso como sua antipatia é justamente o que diverte e encanta as pessoas a sua volta, e aqui encontramos seus paradoxos: Vovó Kyoko é muito querida e parece gostar de sempre emitir os comentários que faz, já esperando que as pessoas se divirtam com eles, ou seja, ela gosta de ser "engraçadinha". Além disso, Vovó esconde por trás de toda sua rispidez uma personalidade protetora para com aqueles que ama, um bom coração, e muitas histórias inusitadas. Segundo Seger (2006), os paradoxos servem para reforçar as consistências do personagem, e não o contrário; estão ali para atribuir maior complexidade à personagem, tornando-a mais palpável.

O próximo passo para a criação de uma boa personagem, que seja palpável e profunda, de acordo com Seger (2006), é a atribuição de valores e crenças à mesma. Assim, Vovó Kyoko possui valores muito bem delineados: mantém um compromisso com a honestidade, preferindo sempre uma verdade dolorida a uma mentira confortável; têm muito respeito aos animais e à natureza; e valoriza o trabalho com vigor, principalmente o trabalho braçal, que é o tipo de atividade que ela mesma pratica. São estes valores que justificam e sustentam as suas ações descritas anteriormente, suas falas, e como se porta frente ao mundo e aos demais. No que diz respeito às emoções, Vovó as possui, é claro, só não é muito boa em demonstrá-las, então sempre o faz a sua própria maneira: ela certamente ama sua família, e acaba demonstrando isso através de sábios e ríspidos conselhos. Ela também é muito protetora, e quando menos esperamos, a encontramos nos defendendo diante de alguma situação difícil. E mesmo sendo conhecida por ser "mão fechada", financeiramente falando, ela gosta de mimar suas netas raras vezes, as chamando em particular e doando alguma quantia em dinheiro escondida, pedindo sigilo sobre o ato em seguida. 
Por último, acrescenta-se detalhes às personagens, como trejeitos, manias e características físicas. No caso de Vovó, por ser nipo-brasileira, ela tem um trejeito que é sua marca registrada e seu maior charme: seu jeito de falar, com um sotaque forte de quem tem o japonês como língua materna, muitas vezes pronunciando palavras com alguns fonemas intensificados, e trocando os " $\mathrm{L}$ " por "R" nas falas. Essa é uma de suas características mais intrínsecas, por isso, foi empregada durante suas falas nas crônicas, e é também o trejeito que marca sua ascendência nipônica. Já em relação às características físicas, Vovó Kyoko pode ser descrita como uma senhora de corpo robusto, coxas e quadris largos, baixa estatura, cabelos castanhos e encaracolados, olhos que demonstram completo desânimo, nariz protuberante, e geralmente exibe um semblante facilmente identificado como "ranzinza". Seu visual é composto por óculos chamativos, de armação gateada, com estampa de onça, brincos dourados, uma blusa folgada vinho, com detalhes em laranja, e uma calça justa num tom de preto dessaturado. Seus calçados são suas tradicionais sandálias confortáveis em um tom neutro, pois Vovó preza por seu conforto já que, por incrível que pareça, é atlética e tem uma disposição incomum se comparada a outras senhoras de sua idade. Tratando-se da paletagem, Vovó exibe um visual mais neutro e básico, com apenas pequenos pontos de cores mais chamativas.

Com o desenvolvimento dos aspectos psicológicos da personagem Vovó Kyoko, criou-se então ela enquanto personagem ilustrada. A seguir pode-se conferir os resultados práticos obtidos a partir deste processo pautado pela metodologia de Seger (2006): a paleta de cores criada (Fig. 3), o modelo estrutural básico da personagem (Fig. 4), suas expressões faciais (Fig.5) e corporais (Fig. 6). 


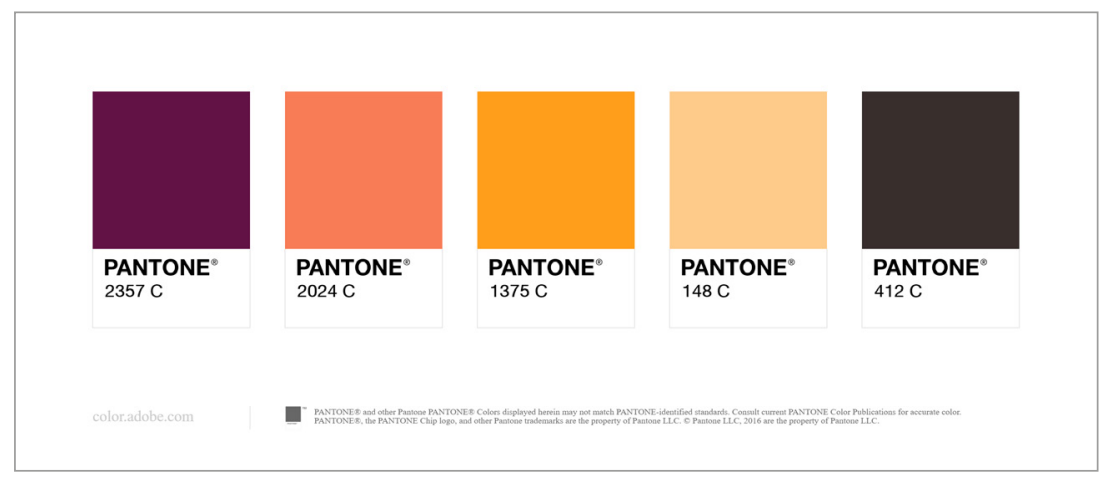

Figura 3. Paleta de cores de Vovó Kyoko. Fonte: arquivo pessoal.

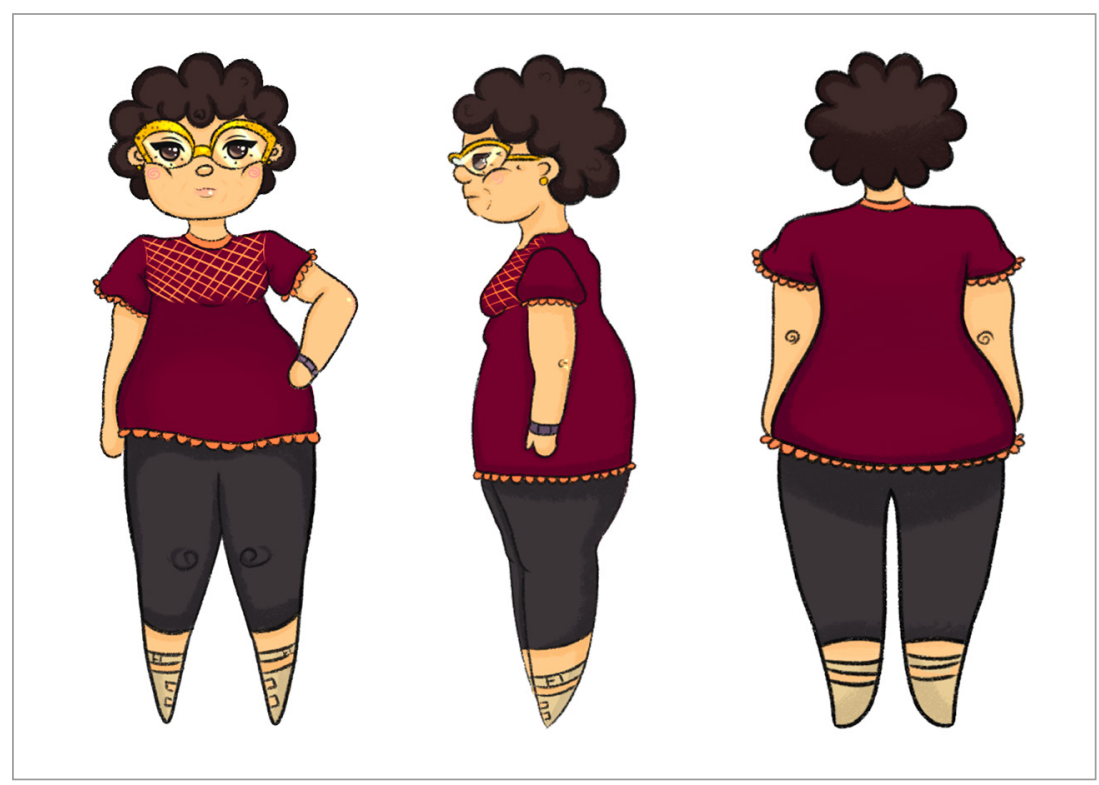

Figura 4. Modelo estrutural de Vovó Kyoko. Fonte: arquivo pessoal.

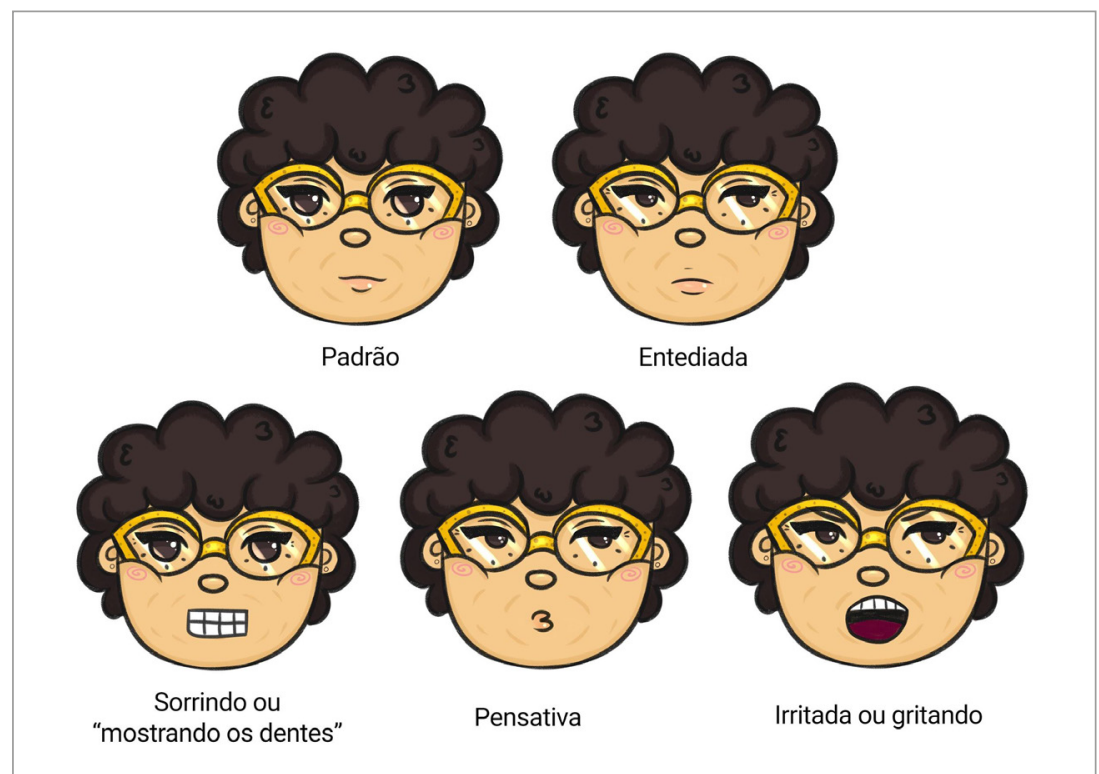

Figura 5. Expressões faciais de Vovó Kyoko. Fonte: arquivo pessoal. 


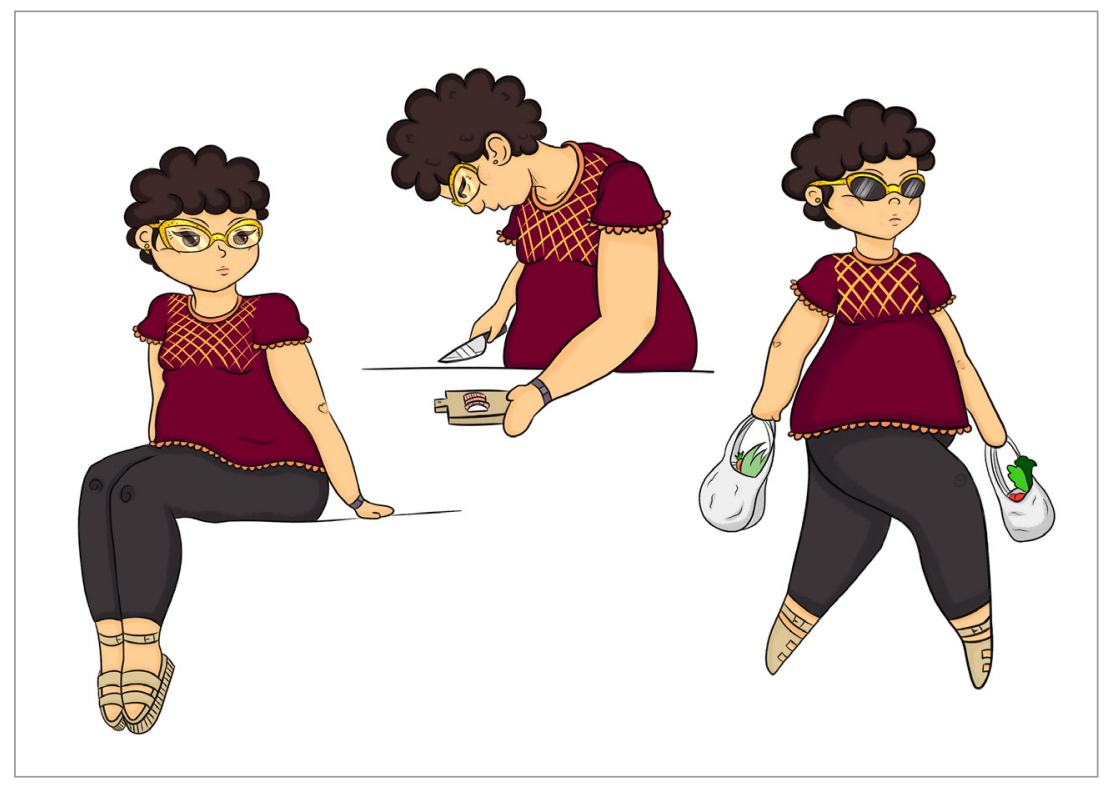

Figura 6. Expressões corporais de Vovó Kyoko. Fonte: arquivo pessoal.

Após a consolidação da prática projetual, pode-se retornar à afirmação básica de Aristóteles (384 a 322 a.C.) de que a personagem procura reproduzir a mimesis do ser humano; afirmação esta ainda mais impactante ao tratar-se de uma personagem biográfica, uma vez que neste processo, observação e análise revelaram-se dois pilares essenciais para a aquisição dos resultados obtidos.

\section{CONSIDERAÇÕES FINAIS}

Este artigo teve como objetivo prático exibir e comentar as etapas do design de uma personagem biográfica, que foi utilizada na criação de um livro ilustrado dedicado à mesma, baseado nas vivências reais da autora ao lado de sua avó; e como objetivo teórico, produzir uma pesquisa de cunho metodológico, a fim de explorar os conhecimentos essenciais para a criação de uma personagem biográfica. Sendo assim, conclui-se através da consolidação da personagem que os objetivos propostos foram atingidos com resultados satisfatórios, que bem representam a realidade da personagem proposta.

Em relação aos caminhos futuros do projeto, pretende-se incorporar a personagem à identidade visual da página 
dedicada à Vovó Kyoko, bem como ilustrar mais crônicas para publicações posteriores, no intuito de aproximar mais o público que acompanha as postagens da personagem, e também de ganhar mais visibilidade para a página.

\section{REFERÊNCIAS BIBLIOGRÁFICAS}

ARISTÓTELES. Poética. Trad. Baby Abrão. São

Paulo: Editorial Nova Cultura, 2000

SEGER, Linda. Como Criar Personagens Inesquecíveis.

São Paulo: Bossa Nova Editora, 2006.

FARIA, Mônica Lima de. Imagem e Imaginário dos Vilões

Contemporâneos. Pontifícia Universidade Católica do Rio Grande do Sul, Porto Alegre, 2012. Disponível em: <https:// drive.google.com/file/d/0BwH27LZgkaK8RG1aMXBKdjhjdk0/ view?ts=5ceebe8c > Acesso em: 04 jun. 2019.

VOVÓ KYOKO. Vovó Kyoko. Miracatu, 10 de maio de 2015. Facebook: kyokothelegend. Disponível em: <https://www. facebook.com/kyokothelegend/> Acesso em: 30 jun. 2019. 